\title{
El trágico vuelo de Ícaro. Entramado mitológico y simbólico que subyace en The Awakening de Kate Chopin
}

Rosario FARAUDO

Universidad Nacional Autónoma de México

Kate Chopin (1851-1904), la autora de The Awakening, pertenecía a una familia acomodada de San Luis Missouri. Su padre era irlandés y su madre descendía de una antigua familia "creole". Los llamados "creole" eran los descendientes de los acadios, un grupo de habla francesa que se estableció en Luisiana tras su expulsión de Canadá en el siglo XVIII.

Kate recibió una educación esmerada (para la época) en la Academia del Sagrado Corazón de su ciudad natal, pero fue su abuela materna quien le infundió el amor a la literatura. Desde muy joven fue una lectora voraz, lo que le proporcionó un amplio panorama de los clásicos ingleses y franceses, y le permitió absorber la atmósfera que se vivía en Europa en las últimas décadas del siglo XIX. Sus intereses culturales eran amplios y variados: la música de Wagner, el teatro de Maeterlinck, Walt Whitman, Flaubert, Baudelaire y otros, así como su contemporáneo Maupassant, por quien la escritora sentía gran admiración. Chopin fue una escritora muy "fin de siècle", lo que en aquella época la identificaba con la revolución artística e intelectual del momento, representada, entre otros, por Oscar Wilde y Aubrey Beardsley, así como con algunos de sus precursores como Swinburne, Pater y Whitman.

La escritora vivió muchos años en Nueva Orleans con su marido, que era parte de una prominente familia "creole", y más tarde en una plantación al norte del estado de Luisiana. Al principio de su carrera literaria tuvo mucho éxito como escritora de narraciones cortas, que en su mayoría se relacionan con la vida en la región donde se asentaba la cultura "creole". Sin embargo, su obra principal es la novela The Awakening (1899), que le ha dado fama recientemente, pese a que permaneció muchos años en el olvido. La publicación de esta obra causó tal escándalo que destruyó la carrera artística de Chopin, y hasta su posición en el mundo social e intelectual. Hubo que esperar cincuenta años para que esta novela recibiera atención de nuevo. Uno de sus biógrafos, Per Seyersted, observa que "fue la primera escritora en el 
país que aceptó la pasión como tema legítimo de ficción seria y franca... que se propuso decir la verdad sobre la vida sumergida de una mujer".'

The Awakening ${ }^{2}$ es la historia de Edna Pontellier, una mujer que pretende alcanzar la libertad y disfrutar su propia sensualidad. En el curso de la narración Edna va descubriendo sus impulsos eróticos, primero hacia un hombre, luego hacia otro, pero lejos de su marido. Escrita en una época de gran represión sexual, especialmente entre las clases media y alta, la reacción general no se hizo esperar. En la sociedad a la que pertenecía la autora prevalecía el ideal de que la mujer "decente" carecía de potencial erótico. La capacidad para experimentar placer sexual era condenada en las esposas por considerarse "impura". El enfoque de Kate Chopin era extraordinariamente atrevido para su tiempo, con el agravante de que resulta claro que las simpatías de la autora están con su heroína. Más allá del interés que actualmente despierta el tema, nos encontramos frente a una novela impregnada de mitología y simbolismo, donde la textura verbal nos ofrece una gran riqueza metafórica.

La heroína está casada con un rico burgués perteneciente a los "creole" de Nueva Orleans. Su vida transcurre con la aparente placidez de la mujer de su clase, cuya obligación principal es la de manifestar el éxito de su marido por medio de su apariencia, su casa, su ocio y sus funciones sociales. En otras palabras, Edna es un objeto más entre las colecciones de Léonce Pontellier.

La obra marca una transición entre naturalismo y simbolismo, ${ }^{3}$ en que Chopin utiliza sus propios elementos simbólicos a través de sueños y evocaciones mitológicas. En el transcurso de la novela se observa una recurrencia de motivos, imágenes y evocaciones míticas que van adquiriendo intensidad y significación al ir reapareciendo, hasta formar una especie de metáfora narrativa. ${ }^{4}$

La primera de estas imágenes la encontramos al principio de la obra, cuando se escucha el parloteo del loro enjaulado que cuelga a un lado de la puerta de la casa donde Leónce Pontellier trata de leer el periódico. Del otro

${ }^{1}$ Citado por Wendy MARTiN en la introducción a New Essays on The Awakening, p. 11.

${ }^{2}$ Kate CHOPIN, The Awakening. Las páginas correspondientes aparecerán entre paréntesis después de cada cita.

${ }^{3}$ Cf. John Carlos Rowe, "The Economics of the Body in Kate Chopin's The Awakening", en Kate Chopin Reconsidered, Beyond the Bayou, ed. de Lynda S. BOREN y Sara DE SAUSSURE DAvis, pp. 117-142.

${ }^{4}$ Se trata de una dimensión paranarrativa donde el proceso de mataforización funciona a nivel de la organización del texto, ya que ciertas secuencias narrativas se articulan, de manera virtual, con una lectura retrospectiva. 
lado de la puerta se encuentra la jaula del sinsonte, cuyas notas parecen contestarle al loro en un idioma que "solamente ellos entienden". Con relación a estos símbolos de domesticidad en sus respectivas jaulas, la autora nos indica que el señor Pontellier "had the privilege of quitting their society when they ceased to be entertaining" (3). Exactamente esto mismo sucederá un poco más tarde cuando Léonce se canse de la compañía de su mujer y decida irse a divertir al casino de un hotel cercano, y cada vez que la situación doméstica no sea de su agrado lo veremos hacer algo parecido. La jaula, entonces, va adquiriendo otras connotaciones: la del matrimonio en que Edna, como los pájaros de Mme. Lebrun, está atrapada. Más adelante Chopin recurrirá a otros pájaros para simbolizar las aspiraciones y el destino final de su heroína.

La familia Pontellier se encuentra pasando el verano en Grand Isle, una colonia de vacaciones en el golfo de México, cerca de Nueva Orleans. Siguiendo la costumbre generalizada entre la burguesía de la época, las mujeres y los niños disfrutan del verano completo, mientras los padres de familia trabajan en la ciudad y acuden a la playa los fines de semana. El establecimiento de la viuda Lebrun, también "creole", es frecuentado por huéspedes de la misma extracción. Su hijo Robert, que obviamente no tiene una ocupación importante en la ciudad, se dedica a ayudar a su madre, entre otras cosas, entreteniendo a los niños y galanteando a las señoras.

Mencioné anteriormente que Edna se ha convertido en una pieza valiosa entre las colecciones de su marido. La primera indicación nos la ofrece Chopin también muy al principio de la novela, cuando Edna regresa de la playa con Robert y Léonce la reprende por bañarse cuando está haciendo tanto sol: "'You are burnt beyond recognition', he added, looking at his wife as one looks at a valuable piece of personal property which has suffered some damage" (4).

Desde el inicio de la obra, el matrimonio es uno de los grandes temas; el matrimonio es monolítico, ineludible, descrito como opresivo y fuente de "ennui", según la percepción de Edna. Además de la sexualidad femenina, la maternidad y el arte, otro de los temas, si bien no es central, es la religión. Sabemos que Edna, originaria de Kentucky, recibió una estricta educación protestante que la agobiaba de niña, y aunque está inmersa en el ambiente católico de los creole, veremos que éste también le resulta sofocante. Durante la estancia en la isla, Chopin inserta el motivo recurrente de "la dama de negro" que no parece tener otro objetivo que vigilar a una pareja de enamorados mientras desgrana las cuentas de su rosario. Ni la dama ni los enamorados tienen nombre, ni voz, lo que los convierte en símbolos representativos de amor y religión. 
En Grand Isle la naturaleza es exuberante y por todas partes encontramos antiguos símbolos de fertilidad, como la fruta, los robles, el pan y el vino. El ambiente está cargado de sensualidad, con el aroma de los naranjos, los jazmines y otras flores. El "despertar" de la protagonista se inicia en el mar, bajo el influjo de su amiga Adèle. Adèle Ratignolle es el prototipo de la mujer madre, que como muchas de las mujeres que veranean en la isla "idolized their children, worshiped their husbands, and esteemed it a holy privilege to efface themselves as individuals and grow wings as ministering angels" (51). Es significativo que Chopin describa a esta bella mujer como "the bygone heroine of romance", lo cual la hace aparecer un tanto anacronica. El matrimonio Ratignolle vive en completa armonía, con sus pequeños hijos, a quien Adèle dedica su vida. Otro personaje femenino importante es Mlle. Reisz, una pianista que veranea en el mismo lugar. Se trata de una mujer solitaria, desconsiderada y poco agradable, con quien Edna se identifica a través de la música. Mlle. Reisz vive con gran austeridad, y dedica su vida al arte. Ninguno de estos dos modelos de mujer resulta satisfactorio para Edna que pretende mucho más de la vida.

Alrededor de la protagonista se identifica un triángulo masculino que forman, por un lado, el joven Robert Lebrun, y por otro, el libertino Alcée Arobin. Ella vive un romance imaginario con Robert, que la galantea durante el verano en Grand Isle y luego desaparece por un tiempo. La sinceridad de las atenciones de Robert es muy cuestionable, como hace notar Adèle. Se trata de una relación eminentemente adolescente, con escapatorias a islas encantadas y encuentros fortuitos que le dan un tono de irrealidad. Robert se hubiera conformado con seguir flirteando con Edna, pero huye de un romance serio. En el otro extremo se encuentra Alcée Arobin, el libertino que le ofrece pasión sin amor. Una vez que Robert ha partido para México y Léonce se encuentra en Nueva York, Edna empieza a frecuentar a Arobin y se involucra sexualmente con él. Es él quien completa el despertar sensual de Edna: "It was the first kiss of her life to which her nature had really responded. It was a flaming torch that kindled desire" (83). La relación con Arobin tampoco satisface a Edna porque comprende desde el primer momento que no ha sido amor lo que ha provocado su respuesta: "it was not love which had held this cup of life to her lips" (83).

Durante la estancia de su marido en Nueva York, Edna decide abandonar la mansión de la calle Esplanade y mudarse a una pequeña casita a la que llama "pigeon house". La paloma, símbolo de domesticidad, constituye una referencia que viene a reforzar el motivo de los pájaros enjaulados con que se inicia la novela. Para la protagonista, éste es un gesto donde ella afirma su independencia, pero en el fondo, la nueva casa sigue siendo la mis- 
ma jaula de siempre, y en cuanto a su autosuficiencia, ésta también es relativa, pues Edna depende de la herencia de su madre que su padre le envía en pequeñas remesas.

Ya he mencionado que la amistad con Mlle. Reisz se ha originado a partir de la música. Durante una velada en que Mlle. Reisz ofrece un concierto en el hotel, la pianista interpreta una pieza que conmueve profundamente a Edna. Ésta evoca en su imaginación la figura de un hombre desnudo a la orilla del mar, observando con resignación el vuelo de un pájaro que se aleja. Esta imagen está cargada eróticamente con la presencia de Robert Lebrun, pero a la vez el pájaro que se aleja parece sugerir un deseo inalcanzable. Esa misma noche Edna aprende a nadar con ayuda de Robert, lo cual le produce gran emoción y es un factor que se puede asociar al dominio que ella va adquiriendo sobre su cuerpo. Por un instante Edna siente terror al ver la distancia que la separa de la playa y dice Chopin que la "golpeó" una fugaz impresión de muerte. Este presagio, de gran contenido metafórico, se hilará posteriormente con el desenlace de la novela. El episodio en que Edna aprende a nadar está cargado de símbolos: al salir del concierto el grupo se dirige a la playa para nadar, caminando bajo los robles iluminados por la luna llena. El aroma de las flores inunda la atmósfera. Es una noche mágica que Robert atribuye al "espíritu del Golfo" pero el escenario también sugiere los bosques de Diana, con quien la luna, los robles y hasta la misma Edna tienen afinidad.

El mar tiene un papel muy importante en esta obra, puesto que es allí donde Edna inicia su viaje interior y despierta su sensualidad. Al igual que otros elementos de la naturaleza, el mar es un símbolo ambiguo, cuyo efecto Chopin evoca con lenguaje de gran belleza. A partir de las descripciones iniciales de su seducción, la atracción del mar adquiere ambigüedad. Su murmullo le llega a Edna "like a loving but imperative entreaty" (14), cuando Robert la invita a nadar. Al atractivo sensual Chopin le añade una invitación transcendente dirigida al alma: "The voice of the sea is seductive: never ceasing, whispering, clamoring, murmuring, inviting the soul to wander for a spell in abysses of solitude; to lose itself in mazes of inward contemplation" (15). El uso de las palabras "abysses" (abismos) y "mazes" (laberintos), sugiere cierto riesgo, que se confirmará más adelante.

Edna tiene aspiraciones artísticas y experimenta con el dibujo durante su estancia en Grand Isle. Al regresar a la ciudad le comunica a Mlle. Reisz su decisión de dedicarse al arte. Mlle. Reisz la relaciona explícitamente con un pájaro cuando le frota la espalda para ver si tiene suficiente fuerza en las alas (82), y le hace una advertencia que Edna confiesa no entender bien: "The bird that would soar above the level plain of tradition and prejudice 
must have strong wings. It is a sad spectacle to see the weaklings bruised, exhausted, fluttering back to earth" (82). La imagen del pajaro sugiere al albatros que Baudelaire identifica con el poeta en "L'Albatros" (Les fleurs $d u \mathrm{mal}$ ). Este símil resuena repetidamente en la obra y constituye una profecía que Chopin articula con el final de la novela, completando la metáfora cuando Edna se dispone a nadar hacia la muerte. En ese momento el único ser vivo en toda la playa es "A bird with a broken wing was beating the air above, reeling, fluttering, circling disabled down, down to the water".

Este motivo nos lleva a relacionar a Edna con Ícaro, que cae al mar cuando el sol derrite la cera de sus alas, al tratar de volar demasiado alto. Existe en el contexto verbal de la novela una red de imágenes que aluden al mito y forman una caja de resonancia que se entreteje con la acción. La escena donde Edna se encuentra frente al mar por última vez está saturada de sol: "The water of the Gulf... gleaming with the million lights of the sun", "she stood naked in the open air, at the mercy of the sun" (113). En este momento en que también el sol es seducción y amenaza, surge el recuerdo de Robert: "she even realized that the day would come when he, too, and the thought of him would melt out of her existence" (113). Robert no es el verdadero objetivo del vuelo de Edna, sino la libertad de ser, algo mucho más difícil de alcanzar. La atracción del infinito vuelve a escucharse en la voz del mar "whispering, clamoring, murmuring, inviting the soul to wander in abysses of solitude" (113). Recordamos que cuando el "ennui" se apodera de Edna, éste surge como un viento helado que parece salir del fondo de una caverna (88). "Cavern", "abysses" y "mazes" son figuras que aluden al laberinto, y que podemos relacionar tanto con el entorno físico de la casa y el marido, como con la tradición y el prejuicio al que se refiere Mlle. Reisz en su advertencia. Como Ícaro, Edna no considera las consecuencias que su ambición puede tener y no escucha las advertencias que su mentor le ha planteado. Esta figura es un tanto ambigua, puesto que Mlle. Reisz, al indicarle a Edna el peligro, se relacionaría con Dédalo, el constructor del laberinto, del cual la pianista está totalmente desligada.

Cuando Edna se dispone a abandonar la mansión de la calle Esplanade, ofrece una cena a sus amigos para celebrar su cumpleaños. La descripción de esta cena está cargada de sensualidad e impregnada de simbolismo. En su artículo "The second coming of Aphrodite" (1983), Sandra Gilbert considera esta escena como un episodio dionisiaco. El comedor está decorado en color dorado, adornado con una profusión de rosas rojas y la bebida frente a cada invitado es del mismo color. La anfitriona preside la mesa vestida de satín dorado y con diamantes en el pelo. Chopin la describe como "the regal woman, the one who rules, who looks on, who stands alone". Gilbert identifica a 
Edna en esta escena con la diosa del amor, aunque la mención explícita aparece en un capítulo posterior, cuando Victor Lebrun (hermano menor de Robert) la describe en estos términos: "Venus rising from the foam could have presented no more entrancing a spectacle than Mrs. Pontellier, blazing with beauty and diamonds at the head of the board" (111). Después de la cena y bajo los efectos del vino, una invitada coloca una guirnalda de rosas rojas y amarillas en la cabeza de Victor, le cubre los hombros con un chal y lo convierte en una figura dionisiaca - "a vision of oriental beauty" (89). Chopin le da al joven un tinte de androginia, pues lo describe como tradicionalmente se haría con una mujer: el chal blanco le cubre el traje oscuro, sus mejillas tienen el color de uvas machacadas, sus ojos brillan y la guirnalda se apoya en sus rizos negros. En ese momento, otro invitado murmura para sí las primeras lineas de un soneto de Swinburne ("A Cameo"): "There was a graven image of Desire / Painted with red blood on a ground of gold".

La alusión a este poema sobre lo insaciable del deseo carnal y el triunfo final de la muerte anuncia la imposibilidad de que Edna encuentre la felicidad a través de la pasión. En medio de la fiesta, Edna siente el viejo "ennui" que se apodera de ella, como un viento helado salido "from some vast cavern wherein discords wailed" (88), el reino subterráneo donde Beardsley encerró a la Venus del siglo XIX.

Encontramos de nuevo a Afrodita cuando Edna se dispone a nadar mar adentro. Cuando se queda desnuda bajo el sol Chopin nos dice: "She felt like some new-born creature, opening its eyes in a familiar world that it had never known" (113). Las olas que se rizan sobre sus pies reiteran la evocación del nacimiento de Venus: "The foamy wavelets curled up to her white feet, and coiled like serpents about her ankles" (113). Persiste aquí el eco de la cena donde Edna apareció como una imagen de Afrodita, sólo que en este momento ella ya se ha desprendido de todo lo que la unía a Léonce Pontellier, hasta de las ropas que lo representaban. Al morir en un mar iluminado por el sol resuena su identificación con Ícaro, pero a su vez esta presencia evoca al Ave Fénix, de cuyas cenizas surgirá una nueva vida, una mujer nueva, dueña de su propio destino. Existe una gran ambigüedad en estos símbolos, puesto que el mar, como espacio mítico, devuelve a Edna al mundo de su infancia - a la pradera de Kentucky - y le permite alcanzar su objetivo de liberación, aunque sea a cambio de la vida. El aire pagano de esta escena nos permite imaginar a Edna naciendo a otra dimensión. Chopin se distancia por completo de sus predecesores, al no permitirnos contemplar a la heroína muerta y enmarcarla en un escenario lleno de luz.

La nota melancólica surge en la descripción del pájaro con el ala rota que cae sobre la arena y donde resuena la metáfora de Mlle. Reisz sobre el artis- 
ta. Regresamos al Albatros de Baudelaire, a Ícaro, y al precio que está pagando Edna por su intento de obtener lo inalcanzable. La salida del laberinto es una posibilidad mucho más viable para el hombre que para la mujer, quien con mayor frecuencia sufrirá las consecuencias.

Chopin parece darnos a entender que su heroína vive en un tiempo y lugar donde el género determina el destino de las personas y donde el vuelo hacia la libertad tiene peligros concretos. En la vida real, también Chopin sufrió las consecuencias de cuestionar los paradigmas de la cultura "victoriana" cuando se atrevió a escribir este libro.

\section{Bibliografía}

BAUDELAIRE, Charleș, Les fleurs du mal. París, Éditions Gründ, 1957.

BEARDSLEY, Aubrey, "Under the Hill (Venus and Tannhäuser)", en Writing of the Nineties. Ed. de Derek STANFORD. Londres, Dent, 1971.

CHOPIN, Kate, The Awakening (1899). Nueva York, W. W. Norton, 1976.

DYER, Joyce, The Awakening. A Novel of Beginnings. Nueva York, Twayne Publishers, 1993.

GILBERT, Sandra, "The Second Coming of Aphrodite", en The Kenyon Review 5, núm. 3. Kenyon College, verano, 1983.

GRANT, Michael, Myths of the Greeks and Romans. Nueva York, Meridian, 1995.

LEFKOWITZ, Mary R., Women in Greek Myth. Londres, G. Duckworth, 1986.

MARTIN, Wendy, ed., New Essays on The Awakening. Nueva York, Universidad de Cambridge, 1988.

PImentel, Luz Aurora, Metaphoric Narration. Toronto, Universidad de Toronto, 1990.

Rowe, John Carlos, "The Economics of the Body in Kate Chopin's The Awakening", en Kate Chopin Reconsidered, Beyond the Bayou. Ed. de Lynda S. BOREN y Sara DE SAUSSURE DAvis. Baton Rouge, Universidad Estatal de Louisiana, 1992, pp. 117-142. 